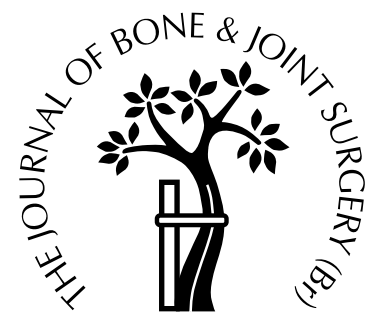

\title{
The intramedullary elongation nail for femoral lengthening
}

\author{
E. García-Cimbrelo, A. Curto de la Mano, E. García-Rey, \\ J. Cordero, R. Marti-Ciruelos \\ From Hospital La Paz and Hospital 12 de Octubre, Madrid, Spain
}

W e have analysed the results of 24 femoral lengthenings in 23 patients operated on between 1993 and 2000, using a gradual elongation intramedullary nail (Albizzia). Of the 23 patients, 22 had femoral deficiency and one was of short stature. Their mean age was 16.9 years. Technical difficulties encountered during the procedure were mild or moderate in $\mathbf{1 8}$ femora and severe in six femora. Distraction was obtained by 15 ratchetings per day (1 mm/day).

There were 18 excellent results although in two patients this was achieved after the development of a pseudarthrosis which required further surgery. There were four good and two fair results in which the lengthening obtained was at least $3 \mathrm{~cm}$ less than had been projected. The consolidation index was 35.2 days/cm. No patient had associated long-term stiffness of the knee.

Femoral lengthening using an elongation nail gives good results and is a comfortable procedure.

J Bone Joint Surg [Br] 2002;84-B:971-7.

Received 6 November 2001; Accepted after revision 30 January 2002

External fixation is commonly used in lengthening of the femur. Circular fixators allow complex and extended lengthening of deficiencies but, compared with the use of monolateral fixators, the technique may be difficult to perform and is poorly tolerated by the patient. ${ }^{1-3}$ External fixation is required for both the distraction and consolidation phases. It places particular demands on patients and

E. García-Cimbrelo, MD, Consultant Orthopaedic Surgeon

J. Cordero, Professor of Orthopaedic Surgery

Orthopaedic Department, Hospital La Paz, Paseo de la Castellana 261, 28046-Madrid, Spain.

A. Curto de la Mano, MD, Consultant Orthopaedic Surgeon

E. García-Rey, MD, Resident

R. Marti-Ciruelos, MD, Orthopaedic Surgeon

Hospital 12 de Octubre (Children's Hospital) Ca. Andalucia km 5.400, 28035-Madrid, Spain.

Correspondence should be sent to Dr E. García-Cimbrelo at Pez Austral 13, $5^{\circ} \mathrm{A}, 28007-$ Madrid, Spain.

(C)2002 British Editorial Society of Bone and Joint Surgery 0301-620X/02/712984\$2.00 there is a high incidence of complications. ${ }^{4-7}$ Premature removal of the fixator may lead to refracture, deformity, shortening or nonunion. ${ }^{5}$

Different intramedullary devices have been used to avoid these problems. An intramedullary nail may be used with an external fixator. ${ }^{5,8,9}$ When the desired length is achieved the intramedullary nail is locked allowing early removal of the external fixator and maintenance of length and alignment. Although the time for which external fixation is required may be reduced with these techniques, secondary problems such as pin-track infection may occur and lead to deep intramedullary infection.

Baumgart, Betz and Schweiberer ${ }^{10}$ described good results in 12 patients using an intramedullary nail with a motorised sliding mechanism which did not require daily adjustments. This system can divide daily distraction into 600 micro intervals. This nail is expensive and to the best of our knowledge is not yet available for general use.

A mechanical intramedullary device, the gradual elonga-

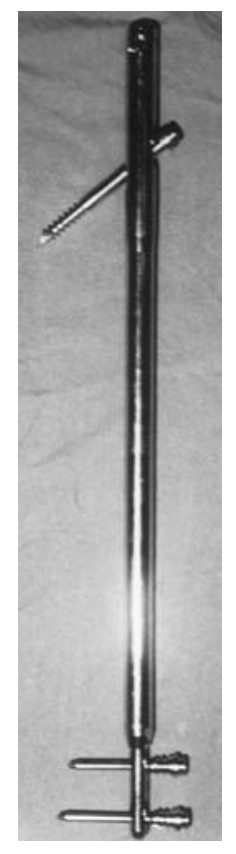

Fig. 1

Photograph showing an Albizzia gradual elongation nail. 
tion nail (GEN), was designed as an alternative to external fixation for progressive lengthening of the femur. ${ }^{11}$ It was subjected to animal experiments and mechanical tests and has now been introduced for clinical use. ${ }^{11,12}$ We have analysed the results obtained with a GEN for femoral lengthening in two centres.

\section{Patients and Methods}

The gradual elongation nail. The GEN (Albizzia: DePuy, Villeurbanne, France) comprises two telescoping cylinders which are connected by a ratchet system (Fig. 1). It is lengthened by rotating movements of the limb. ${ }^{11}$ Each ratcheting lengthens the system by $0.07 \mathrm{~mm}$, or about $1 \mathrm{~mm}$ for every 15 ratchetings. There is a key to limit angular rotation between the cylinders, a preoperative prefixed locking device to prevent movement at the end of the period of lengthening, and a device at the level of the proximal lock to dynamise the regeneration of bone. This allows cyclical loading of the regenerate with muscle contraction or on walking, without unlocking the nail. ${ }^{12}$

Lengthenings of between 60 and $100 \mathrm{~mm}$ may be achieved. Proximal locking is obtained with a $5.5 \mathrm{~mm}$ diameter screw and distal locking with two $3.5 \mathrm{~mm}$ diameter screws for nails of $11 \mathrm{~mm}$ diameter or two $4.5 \mathrm{~mm}$ diameter screws for those of 13 or $15 \mathrm{~mm}$ diameter.

Patients. Between September 1993 and September 2000 we carried out 24 femoral lengthenings in 23 patients. Use of the GEN was contraindicated in patients with open growth plates, the elderly, those with poor periosteum as in some post-traumatic deficiencies, and in the presence of an unstable hip or knee, a major femoral deformity, and/or a narrow femoral medullary canal with a thin cortex. The mean length of follow-up was for 44.7 months (12 to 84). The mean age of the patients at the time of operation was 16.9 years (11 to 34$)$. There were 12 men and 11 women. Many had undergone previous surgery (Table I).

A total of 22 patients underwent lengthening because of a limb deficiency (Fig. 2). Another with short stature required bilateral lengthening of the femur and tibia. The cause of the deficiencies was classified according to Paley et $^{\mathrm{al}^{5}}$ as congenital with simple femoral hypoplasia in nine cases, post-traumatic secondary to a fracture in two and developmental due to poliomyelitis, Ollier's disease, growth arrest as a result of a fracture, infection, avascular necrosis, or short stature due to deficiency of growth hormone in 13.

The preoperative assessment of the technical difficulty of the lengthening procedure was made according to the criteria of Paley et $\mathrm{al}^{5}$ as mild (6), moderate (12) or severe (6). This assessment is based on possible complications of the procedure and include age, femoral deformity, other operations which may be required in the same bone, associated tibial lengthening, instability of the hip or knee, fixed flexion deformity of the knee, osteoarthritis of the hip or knee, the quality of the bone and soft tissue, and associated medical conditions.

Preoperative planning. The size of the nail and the level

Table I. Preoperative details of the 23 patients who underwent femoral lengthening with a gradual intramedullary elongation nail

\begin{tabular}{|c|c|c|c|c|c|c|}
\hline Case & $\begin{array}{l}\text { Age } \\
\text { (yrs) }\end{array}$ & Gender & Aetiology (*) & Previous surgery & $\begin{array}{l}\text { Limb-length } \\
\text { discrepancy } \\
\text { (cm) }\end{array}$ & $\begin{array}{l}\text { Level of } \\
\text { difficulty }\end{array}$ \\
\hline 1 & 13 & $\mathrm{~F}$ & Congenital short femur (C) & - & 4.5 & Mild \\
\hline 2 & 13 & $\mathrm{~F}$ & Congenital short femur (C) & - & 5.0 & Mild \\
\hline 3 & 16 & $\mathrm{M}$ & Poliomyelitis (D) & - & 4.6 & Mild \\
\hline 4 & 18 & M & Hemihypoplasia (C) & Ilizarov & 5.0 & Severe \\
\hline 5 & 17 & M & Congenital short femur (C) & - & 4.4 & Moderate \\
\hline 6 & 15 & $\mathrm{~F}$ & Ollier's disease (D) & Ilizarov & 4.0 & Moderate \\
\hline 7 & 17 & M & Traumatic growth arrest (D) & - & 5.0 & Mild \\
\hline 8 & 34 & $\mathrm{~F}$ & Poliomyelitis (D) & Tenotomies & 6.0 & Severe \\
\hline 9 & 15 & M & Congenital short femur (C) & Chiari osteotomy & 6.5 & Severe \\
\hline 10 & 16 & M & Congenital short femur (C) & Ilizarov & 6.0 & Moderate \\
\hline 11 & 14 & M & Congenital short femur (C) & - & 4.2 & Mild \\
\hline 12 & 28 & M & Congenital short femur (C) & - & 5.3 & Moderate \\
\hline 13 & 15 & $\mathrm{~F}$ & Congenital short femur (C) & - & 4.8 & Moderate \\
\hline 14 & 16 & M & Hip arthritis (D) & Hip arthrotomy & 3.6 & Moderate \\
\hline $15 \dagger$ & 17 & $\mathrm{~F}$ & Short stature (D) & - & 10.0 & Severe \\
\hline $16 \dagger$ & 17 & $\mathrm{~F}$ & Short stature (D) & - & 10.0 & Severe \\
\hline 17 & 16 & $\mathrm{~F}$ & Congenital dislocation of the hip (D) & Hip necrosis & 4.0 & Moderate \\
\hline 18 & 17 & $\mathrm{~F}$ & Femoral fracture $(\mathrm{T})$ & Nail & 6.0 & Moderate \\
\hline 19 & 16 & M & Septic growth arrest (D) & - & 6.0 & Moderate \\
\hline 20 & 16 & $\mathrm{~F}$ & Traumatic growth arrest (D) & - & 4.5 & Moderate \\
\hline 21 & 15 & $\mathrm{~F}$ & Femoral fracture $(\mathrm{T})$ & Nail & 6.0 & Severe \\
\hline 22 & 13 & M & Traumatic growth arrest (D) & Osteosynthesis & 6.2 & Mild \\
\hline 23 & 11 & $\mathrm{~F}$ & Traumatic growth arrest (D) & Valgus osteotomy & 6.5 & Moderate \\
\hline 24 & 19 & M & Multiple exostosis (D) & Exostosis resection & 3.5 & Moderate \\
\hline
\end{tabular}




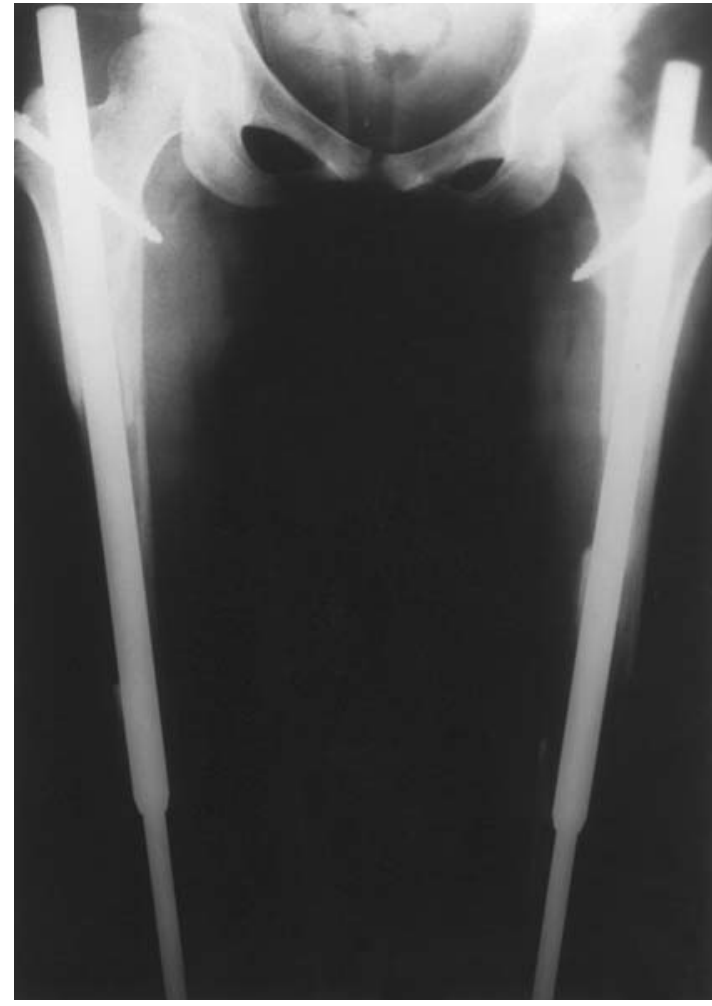

Fig. 2a
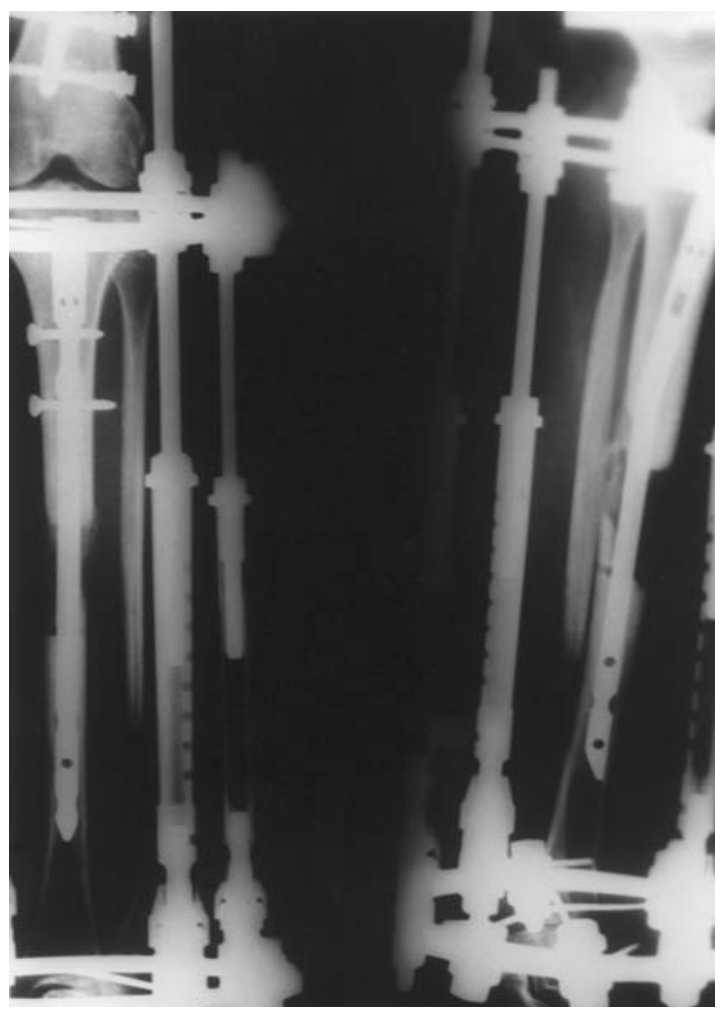

Fig. 2c

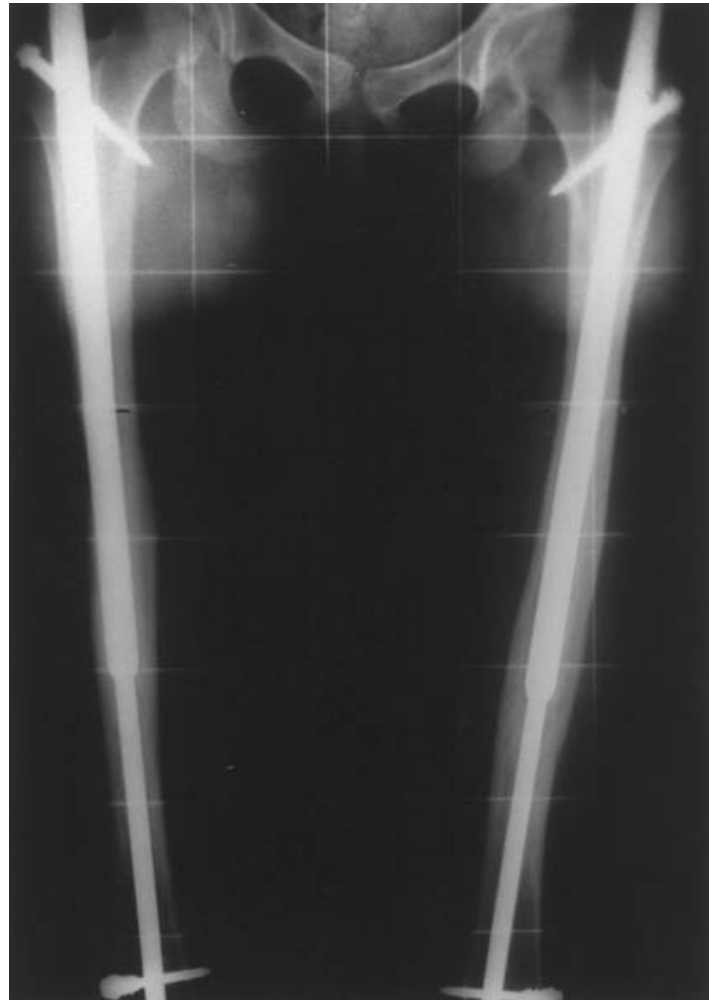

Fig. $2 b$

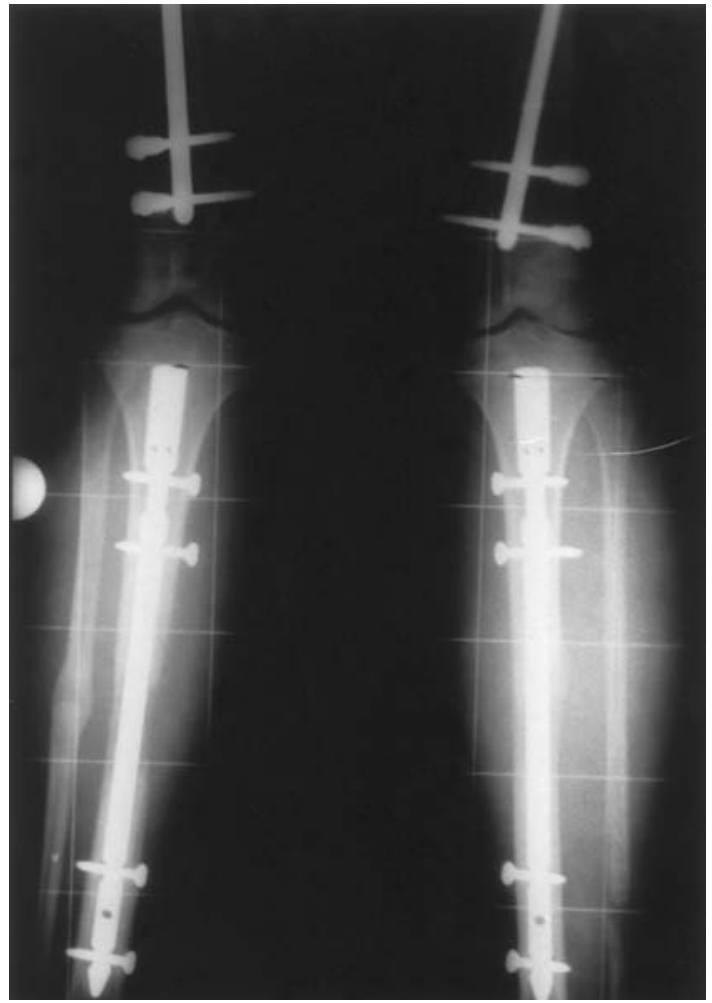

Fig. 2d

Cases 15 and 16. Bilateral femoral and tibial lengthenings in a 17-year-old girl with short stature. Albizzia GENs were used for the femoral lengthenings and unreamed tibial nails associated with Ilizarov fixators for the tibial lengthenings. Radiographs show a) femoral lengthenings during distraction, b) at the end of the treatment, c) tibial lengthenings during distraction, and d) at the end of the treatment. 
of the osteotomy are established for each patient. Selection of the nail is based on the length of the femur, the diameter of the medullary canal and the amount of lengthening which is required. Teleroentgenography of the lower limbs is necessary. Post-traumatic deficiencies require lateral radiographs to identify femoral deformities. We used CT in some difficult cases, since determination of limb length by this means is simple and accurate and the entire pelvis and lower limbs can be seen. ${ }^{13}$

The clinical and radiological data were sent to the manufacturer, who calculated the level of the osteotomy, prepared an approximate-sized nail and created a template of the femur to facilitate surgery.

Operative technique. After reaming, internal osteotomy with an intramedullary saw at a preselected site was undertaken in such a way as to preserve as much periosteum as possible. The bone was distracted at the site of the osteotomy before introduction of the nail. At the end of the operation $5 \mathrm{~mm}$ of lengthening were obtained.

Toe-touch weight-bearing with two crutches was allowed initially after the operation. Distraction was started on the fifth postoperative day at a rate of $1 \mathrm{~mm}$ /day with five ratchetings, three times per day. At the end of the predetermined gain, rotation and further elongation were automatically blocked by the fixed locking system which had been set to prevent further movement when the desired lengthening had been achieved. The dynamisation system makes it unnecessary to unlock the nail. Full weightbearing without crutches is allowed after newly formed bone has bridged two cortices as seen on radiographs.

Evaluation criteria. The procedure was evaluated accord- ing to the clinical and radiological criteria developed by Paley et al. ${ }^{5}$ The scores were rated as excellent, good, fair or poor on the basis of six criteria: range of movement of the knee, the amount of lengthening obtained, gait, the lateral distal angle, pain, and the ability to perform daily or work activities. Lengthening was assessed by comparing the actual amount achieved with the initial goal.

Complications were again classified on the criteria Paley et $\mathrm{al}^{5}$ as intraoperative difficulties, obstacles, which were defined as difficulties which arise during treatment and which can be treated successfully by further surgery, and true complications, temporary or permanent.

The radiological consolidation endpoint was defined as occurring when the bone in the distraction gap had healed and three of four cortices had been bridged on anteroposterior (AP) and lateral radiographs. ${ }^{14}$ The time to consolidation was measured as the period from the operation to the endpoint, and included the distraction and consolidation phases. We also calculated the radiological consolidation index which is the time to consolidation per centimetre of distraction gap.

\section{Results}

Operative details and complications. The osteotomy was transverse in 15 femora, oblique in six (with a third fragment in cases 6 and 11) and open in three. Three open osteotomies were required due to failure of the intramedullary saw because of breakage (case 13) and disassembly (cases 18 and 19). No associated surgical procedures were required. Temporary palsy of the peroneal

Table II. The results of the 23 patients who underwent femoral lengthening with a gradual intramedullary elongation nail

\begin{tabular}{|c|c|c|c|c|c|}
\hline Case & Corticotomy & $\begin{array}{l}\text { Limb length obtained/ } \\
\text { projected } \\
\text { (cm) }\end{array}$ & $\begin{array}{l}\text { Duration of } \\
\text { distraction } \\
\text { (days; days/cm) }\end{array}$ & $\begin{array}{l}\text { Time of } \\
\text { consolidation } \\
\text { (days; days/cm) }\end{array}$ & Result \\
\hline 1 & Transverse & $4.5 / 4.5$ & 48 (10.7) & $147(32.7)$ & Excellent \\
\hline 2 & Transverse & $5 / 5$ & $0(10)$ & $170(34)$ & Excellent \\
\hline 3 & Transverse & $4.6 / 4.6$ & $52(11.3)$ & $220(47.8)$ & Excellent \\
\hline 4 & Transverse & $5 / 5$ & $60(12)$ & $240(48)$ & Good \\
\hline 5 & Transverse & $4.4 / 4.4$ & $45(10.2)$ & $150(34.1)$ & Excellent \\
\hline 6 & Oblique & $2 / 4$ & $28(14)$ & $92(45)$ & Good \\
\hline 7 & Transverse & $5 / 5$ & $50(10)$ & $150(30)$ & Excellent \\
\hline 8 & Oblique & $2 / 6$ & $35(17)$ & $180(90)$ & Fair \\
\hline 9 & Transverse & $6 / 6.5$ & $62(10.3)$ & $220(36.3)$ & Good \\
\hline 10 & Transverse & $6 / 6$ & $65(10.8)$ & $210(35)$ & Excellent \\
\hline 11 & Oblique & $4 / 4.2$ & $47(11.75)$ & $95(23.7)$ & Good \\
\hline 12 & Transverse & $4.6 / 5.7$ & $60(13.3)$ & $150(32.6)$ & Excellent \\
\hline 13 & Open & $4.8 / 4.8$ & $45(9.8)$ & Pseudarthrosis & Excellent \\
\hline 14 & Transverse & $3.6 / 3.6$ & 40 (11.1) & $125(34.7)$ & Excellent \\
\hline 15 & Oblique & $10 / 10$ & $150(15)$ & $260(26)$ & Excellent \\
\hline 16 & Oblique & $10 / 10$ & $150(10)$ & $260(26)$ & Excellent \\
\hline 17 & Transverse & $4 / 4$ & $40(10)$ & $120(30)$ & Excellent \\
\hline 18 & Open & $3 / 6$ & 35 (11.7) & $100(33.39)$ & Fair \\
\hline 19 & Open & $6 / 6$ & 78 (13) & Pseudarthrosis & Excellent \\
\hline 20 & Oblique & $4.5 / 4.5$ & $45(10)$ & $150(33.3)$ & Excellent \\
\hline 21 & Transverse & $6 / 6$ & $60(10)$ & $240(40)$ & Excellent \\
\hline 22 & Transverse & $6.2 / 6.2$ & $60(9.7)$ & $120(19.3)$ & Excellent \\
\hline 23 & Transverse & $6 / 6.5$ & $62(10.3)$ & $150(25)$ & Excellent \\
\hline 24 & Transverse & $3.5 / 3.5$ & $28(8)$ & $66(18.8)$ & Excellent \\
\hline
\end{tabular}


nerve was seen in two patients (cases 2 and 21) which resolved after three months. There was no failure of the GEN lengthening mechanism.

There was no soft-tissue infection or delayed wound healing. Late infection around a distal screw was seen in one femur which had been previously lengthened using a circular external fixator (case 6). In this patient, who had Ollier's disease, the intended lengthening was not fully obtained because of painful ratcheting. The infection resolved after removal of the implant when bony consolidation had been obtained.

Five patients (cases 6, 8, 12, 16 and 18) complained that pain during the first few days made ratcheting difficult. Epidural analgesia was used in two patients (cases 12 and 16) about one week later. The other three refused analgesia and the lengthening was halted. All three, however, considered the outcome to be satisfactory, and the results were considered to be fair in two patients and good in one

Clinical results. According to the criteria of Paley et $\mathrm{al}^{5}$ there were 18 excellent results; in two patients (cases 13 and 19) this was after the development of a pseudarthrosis which required a further operation. There were four good and two fair results in which the intended lengthening was not obtained by at least $3 \mathrm{~cm}$ (Table II). There were no axial

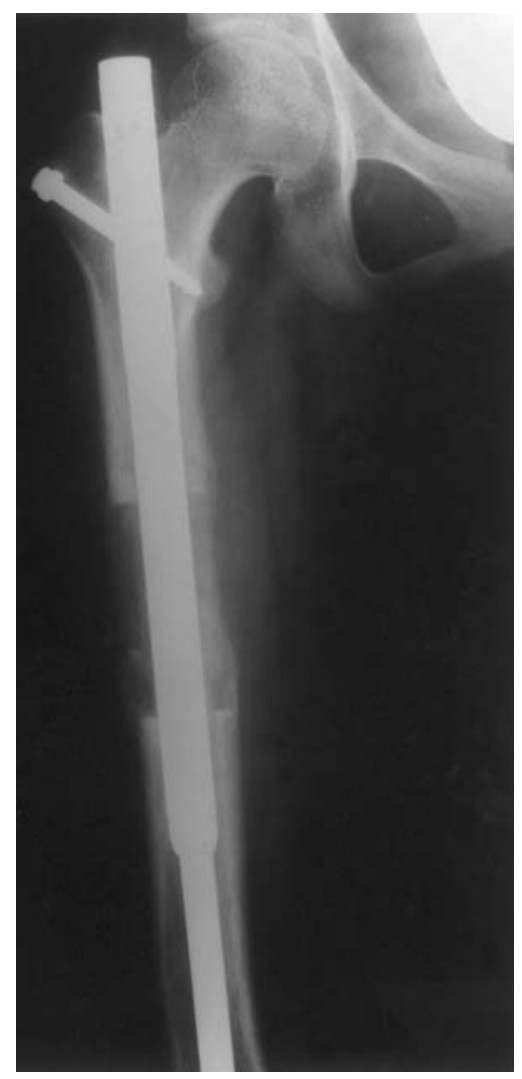

Fig. 3

Case 23. Radiograph showing an excellent result in an 11-year-old girl. femoral deformities (Fig. 3). A valgus tibial deformity required a posterior tibial osteotomy in one femur with hemihypoplasia (case 4). The preoperative knee function was regained in all patients. The extensor mechanism was not impaired, and there was no stiffness of the knee. The gait of all patients was normal after one year.

The mean lengthening obtained was $5.0 \mathrm{~cm}$ (2 to 10$)$, compared with a mean projected lengthening of $5.5 \mathrm{~cm}(3.5$ to 10 ). In three patients (cases 6,8 and 18) lengthening was $2 \mathrm{~cm}$ less than projected because of painful ratcheting, but these patients were satisfied with the outcome. The mean period of distraction was 56.9 days (28 to 150) with a mean distraction index of 11.1 days/cm (8.0 to 17.0$)$. The mean time to consolidation was 164.3 days in the 22 femora in which bone healing had been obtained and the mean consolidation index was 35.2 days/cm. There was gross periosteal hypertrophy with early bony union and an excellent result in one patient (case 22) in whom a previous distal femoral physeal fracture had been treated by open reduction and internal fixation with Kirschner wires. The GENs were removed after consolidation. In one femur with an excellent result the nail was found to be broken and only the proximal part could be removed (case 1).

Late complications. There were few complications. Delayed bone healing was observed in two femora in which an open osteotomy had been undertaken. One of these patients (case 13) developed a pseudarthrosis with fracture of the nail while the other (case 19) had delayed healing with bending of the nail. Consolidation was obtained in both with a final excellent result after replacing the GEN with a locked reamed nail and autografting (Fig. 4). In the third femur (case 18) which required an open osteotomy because of disassembly of the saw, ratcheting was painful and the intended length was not achieved.

\section{Discussion}

The Albizzia GEN was designed as an alternative to external fixation for progressive lengthening of the femur. The theoretical advantages are that it is well tolerated, infections are uncommon, axial deviation is avoided, and internal osteotomy does not disturb the blood supply in the periosteum. It is contraindicated in patients with open growth plates, the elderly, or patients with an unstable hip or knee, poor periosteum, recent infection or major femoral deformities. Multiplanar corrections may be addressed with a special nail (3D-Albizzia). ${ }^{15}$

There was no long-term stiffness of the knee in our patients. This complication has been frequently reported in femoral lengthening using an external fixator. ${ }^{6,7}$ The improved results may be because the muscle is not transfixed. $^{10}$

There was no failure of the lengthening mechanism in our series. Pain made ratcheting difficult in five femora; it settled with epidural analgesia in two. Catagni ${ }^{16}$ has reported the frequent use of analgesics by Ilizarov in the 


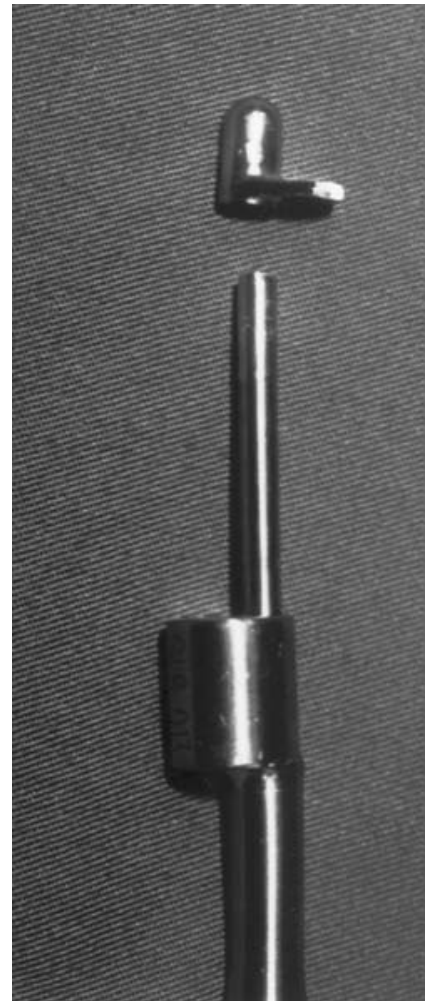

Fig. $4 \mathrm{a}$

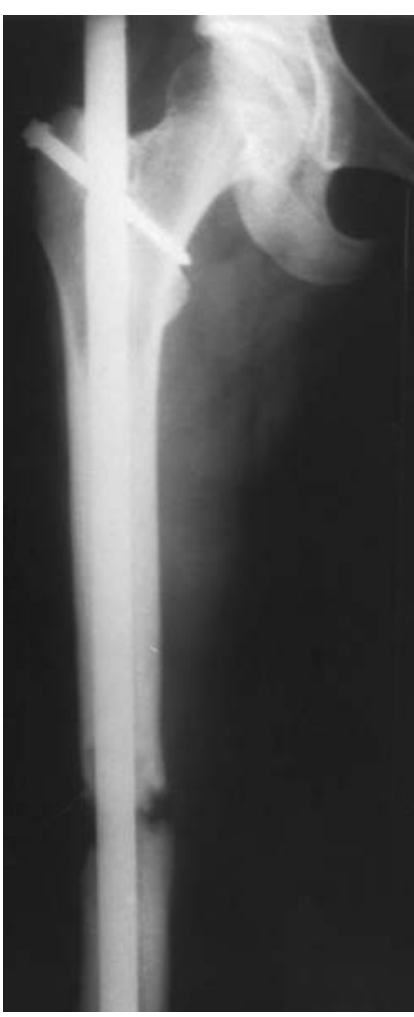

Fig. 4b

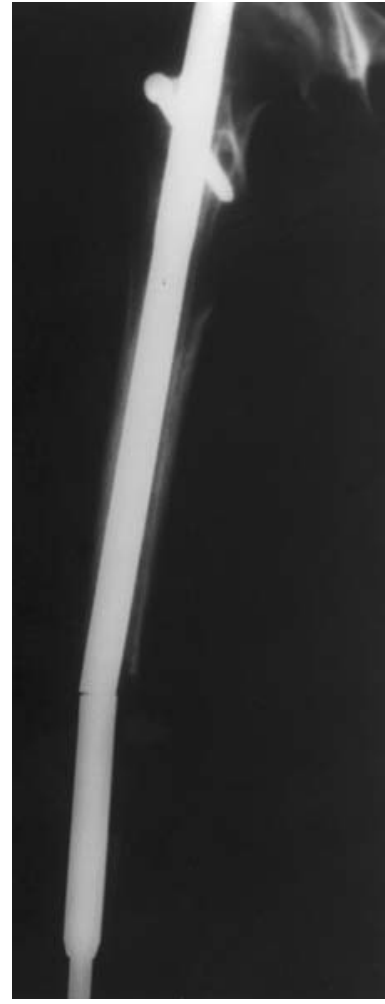

Fig. 4c

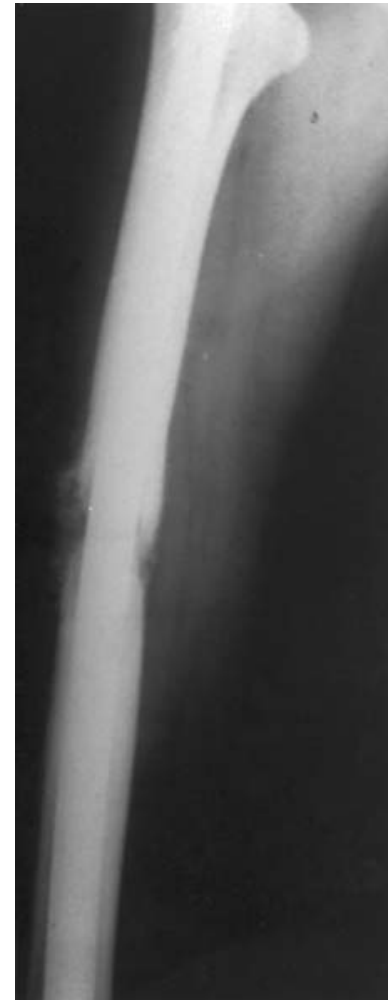

Fig. 4d

Case 13. Figure 4a - An open femoral osteotomy was required because of the failure of an intramedullary saw. Figures $4 \mathrm{~b}$ and $4 \mathrm{c}$ - This led to a pseudarthrosis (b) which provoked failure of the nail (c). Figure $4 \mathrm{~d}$ - A reamed universal locked nail and autografting were used to resolve the complication.

management of pain during limb-lengthening. The pain probably arises from stretching of the periosteum, which may remain partly intact after internal osteotomy. After the pain of the initial postoperative period had settled, lengthening was easily obtained. The rate of distraction was $1 \mathrm{~mm} /$ day as was recommended by Ilizarov for external fixators. ${ }^{17,18}$ It is known that rates of more than $1 \mathrm{~mm} /$ day may exceed the potential for vascular ingrowth at a diaphyseal site ${ }^{19,20}$ and this rate seems to be accepted by vessels and nerves. ${ }^{21}$

In order to ensure separation of the bone ends and to prevent premature consolidation, we checked that the osteotomy was complete by bending the bone backwards and forwards at the site of the division. Premature consolidation of the regenerate occurred in the series reported by Paley et $\mathrm{al}^{5}$ and the high rate of premature consolidation and non-separation associated with lengthening over an intramedullary nail was thought to occur because the bone had not been reamed. Ilizarov emphasised the importance of preserving the endosteal blood supply in distraction osteogenesis. ${ }^{17,18}$ The good results observed in our series confirm that a reamed intramedullary nail does not prevent bone formation in a distraction gap. Internal osteotomy and reaming of the endosteum were followed by regeneration of bone. It has been suggested that any slowing of the formation of new bone due to damage to the medullary circula- tion may be compensated for by the effects of revascularisation after reaming and the better stability provided by fixation with a nail. ${ }^{5}$ Different series have shown that the medullary canal may be reamed or curetted without adverse consequences, but the periosteum is critical for the formation of a regenerate callus. ${ }^{10,22,23}$ Guichet et $\mathrm{al}^{23}$ observed that in 18 growing rabbits the periosteum alone forms a larger callus with a higher mineral content than bone marrow alone while destruction of both marrow and periosteum results in the absence of bone formation in the area of the distraction.

The most severe complications were seen after the open osteotomies which were required after failure of the intramedullary saw. Open osteotomy disturbs periosteal vascularisation and delays bone healing. Two femora developed a pseudarthrosis with failure of the nail and required an intramedullary locked reamed nail and autografting. The periosteum is the major contributor to osteogenesis during distraction since it is the main source of vascularity, and its careful preservation is essential to bone healing. ${ }^{10,19,23-27}$ Methods which disrupt the periosteum, such as corticotomies and osteotomies, may lead to decreased osteogenesis. $^{23,28}$

With the use of the external fixator, lengthening occurs along the mechanical axis of the femur, whereas lengthening over an intramedullary nail takes place along the 
anatomical axis. Theoretically, this would place the centre of the knee in a more medial position and may produce a valgus deformity of the knee. ${ }^{5}$ There was an increase of a previous valgus deformity in one patient who had a good result after a corrective tibial osteotomy.

Femoral lengthening using a GEN gives good results and is comfortable for most patients. There has been no failure of the lengthening mechanism in our series. Open osteotomy was the most severe complication and was associated with a pseudarthrosis and breakage of the nail. Initial ratchetings can be painful, and adequate analgesia is required.

No benefits in any form have been received or will be received from a commercial party related directly or indirectly to the subject of this article.

\section{$\underline{\text { References }}$}

1. Aldegheri R, Renzi-Brivio L, Agostini S. The callotasis method of limb lengthening. Clin Orthop 1989;241:137-45.

2. Price CT, Cole JD. Limb lengthening by callotasis for children and adolescents: early experience. Clin Orthop 1990;250:105-11.

3. Price CT, Mann JW. Experience with the Orthofix device for limb lengthening. Orthop Clin North Am 1991;22:651-61.

4. Aquerreta JD, Forriol F, Cañadell J. Complications of bone lengthening. Int Orthop 1994;18:299-303.

5. Paley D, Herzenberg JE, Paremain G, Bhave A. Femoral lengthening over an intramedullary nail: a matched-case comparison with Ilizarov lengthening. J Bone Joint Surg [Am] 1997;79-A:1464-80.

6. Herzenberg JE, Scheufele PT, Paley D, Bechtel R, Tepper S. Knee range of motion in isolated femoral lengthening. Clin Orthop 1994;301:49-54.

7. García-Cimbrelo E, Olsen B, Ruiz-Yagüe M, Fernandez-Baílllo N, Munuera-Martínez L. Ilizarov technique: results and difficulties. Clin Orthop 1992;283:116-23.

8. Lin CC, Huang SC, Liu TK, Chapman MW. Limb lengthening over an intramedullary nail: an animal study and clinical report. Clin Orthop 1996;330:208-16.

9. Simpson AHRW, Cole AS, Kenwright J. Leg lengthening over an intramedullary nail. J Bone Joint Surg [Br] 1999;81-B:1041-5.

10. Baumgart R, Betz A, Schweiberer L. A fully implantable motorized intramedullary nail for limb lengthening and bone transport. Clin Orthop 1997;343:135-43.
11. Guichet JM, Grammont PM, Trouilloud P. A nail for progressive lengthening: an animal experiment with a 2 year follow-up. Chirurgie 1992;118:405-10.

12. Guichet JM, Casar RS. Mechanical characterization of a totally intramedullary gradual elongation nail. Clin Orthop 1997;337:281-90.

13. Glass RBJ, Poznanski AK. Leg-length determination with biplanar CT scanograms. Radiology 1985;156:833-4.

14. Fischgrund J, Paley D, Suter C. Variables affecting time to bone healing during limb lengthening. Clin Orthop 1994;301:31-7.

15. Guichet J-M. Leg lengthening and correction of deformity using the femoral Albizzia nail. Orthopäde 1999;28:1066-77.

16. Catagni MA. Upgrade of the Ilizarov method. In: Jakob RP, Fulford P, Horan F, eds. European Instructional Course Lectures, Vol. 4. London: The British Editorial Society of Bone and Joint Surgery, 1999:152-58

17. Ilizarov GA. The tension-stress effect on the genesis and growth of tissues. Part II. The influence of the rate and frequency of distraction. Clin Orthop 1989;239:263-85.

18. Ilizarov GA. Clinical application of the tension-stress effect of limb lengthening. Clin Orthop 1990;250:8-26.

19. Aronson J, Shen X. Experimental healing of distraction osteogenesis comparing metaphyseal with diaphyseal sites. Clin Orthop 1994;301:25-30

20. Ganey TM, Klotch DW, Sasse J, Ogden JA, Garcia T. Basement membrane of blood vessels during distraction osteogenesis. Clin Orthop 1994;301:132-8.

21. Ippolito E, Peretti G, Bellocci M, et al. Histology and ultrastructure of arteries, veins, and peripheral nerves during limb lengthening. Clin Orthop 1994;308:54-62.

22. Kojimoto H, Yasui N, Goto T, Matsuda S, Shimomura Y. Bone lengthening in rabbits by callus distraction: the role of periosteum and endosteum. J Bone Joint Surg [Br] 1988;70-B:543-9.

23. Guichet J-M, Braillon P, Bodenreider O, Lascombes P. Periosteum and bone marrow in bone lengthening: a DEXA quantitative evaluation in rabbits. Acta Orthop Scand 1998;69:527-31.

24. Aronson J, Harrison BH, Stewart CL, Harp JH Jr. The histology of distraction osteogenesis using different external fixators. Clin Orthop 1989;241:106-16.

25. Aronson J. Temporal and spatial increases in blood flow during distraction osteogenesis. Clin Orthop 1994;301:124-31.

26. Delloye C, Delefortrie G, Coutellier L, Vincent A. Bone regenerate formation in cortical bone during distraction lengthening: an experimental study. Clin Orthop 1990;250:30-42.

27. Yasui N, Kojimoto $\mathbf{H}$, Sasaki $\mathbf{K}$, et al. Factors affecting callus distraction in limb lengthening. Clin Orthop 1993;293:55-63.

28. Frierson M, Ibrahim K, Boles M, Boté H, Ganey T. Distraction osteogenesis: a comparison of corticotomy techniques. Clin Orthop 1994;301:19-24. 